\title{
Search and Insights into Novel Genetic Alterations Leading to Classical and Atypical Werner Syndrome
}

\author{
Junko Oshima ${ }^{a}$ Fuki M. Hisama ${ }^{b}$ \\ ${ }^{a}$ Department of Pathology and ${ }^{b}$ Division of Medical Genetics, Department of Medicine, University of Washington, \\ Seattle, Wash., USA
}

\section{Key Words}

Werner syndrome · Atypical Werner syndrome . Hutchinson-Gilford progeria syndrome - Genetics . Mutation · Cancer - Cardiovascular disease

\begin{abstract}
Segmental progeroid syndromes are a group of disorders with multiple features resembling accelerated aging. Adultonset Werner syndrome (WS) and childhood-onset Hutchinson-Gilford progeria syndrome are the best known examples. The discovery of genes responsible for such syndromes has facilitated our understanding of the basic mechanisms of aging as well as the pathogenesis of other common, agerelated diseases. Our International Registry of Werner Syndrome accesses progeroid pedigrees from all over the world, including those for whom we have ruled out a mutation at the WRN locus. Cases without WRN mutations are operationally categorized as 'atypical WS' (AWS). In 2003, we identified LMNA mutations among a subset of AWS cases using a candidate gene approach. As of 2013, the Registry has 142 WS patients with WRN mutations, 11 AWS patients with LMNA mutations, and 49 AWS patients that have neither WRN nor LMNA mutations. Efforts are underway to identify the responsible genes for AWS with unknown genetic causes. While WS and AWS are rare disorders, the causative genes have been shown to have much wider implications for cancer, cardiovascular disease and the biology of aging. Re-
\end{abstract}

markably, centenarian studies revealed WRN and LMNA polymorphic variants among those who have escaped various geriatric disorders.

(c) 2014 S. Karger AG, Basel

\section{International Registry of Werner Syndrome}

The International Registry of Werner Syndrome (Department of Pathology, University of Washington, Seattle, Wash., USA) (www.wernersyndrome.org) was established in 1988 and has been recruiting segmental progeroid syndrome cases from physicians around the world (fig. 1). The original purpose of the Registry was to collect samples from Werner syndrome (WS) patients for positional cloning of $W R N$ [1]. After the successful cloning of $W R N$ gene, we began accepting progeroid cases that met different subsets of the diagnostic criteria [2] with the goal of identifying unusual $W R N$ mutations and mutations at other loci that resulted in WS-like symptoms.

Some of the patients were initially referred to our International Registry for molecular diagnosis of WS but were shown to have wild-type WRN coding regions and normal levels and sizes of the WRN protein as shown by Western blot analysis. Such cases were operationally categorized as having atypical WS (AWS). As of 2013, the Registry has recruited 142 cases of classical WS with documented WRN mutations, 11 cases of AWS with LMNA

\section{KARGER}

E-Mail karger@karger.com

www.karger.com/ger
(C) 2014 S. Karger AG, Basel

0304-324X/14/0603-0239\$39.50/0
Junko Oshima, $\mathrm{MD}, \mathrm{PhD}$

Department of Pathology University of Washington

Box 357470 , HSB K-543

Seattle, WA 98195-75470 (USA)

E-Mail picard@u.washington.edu 


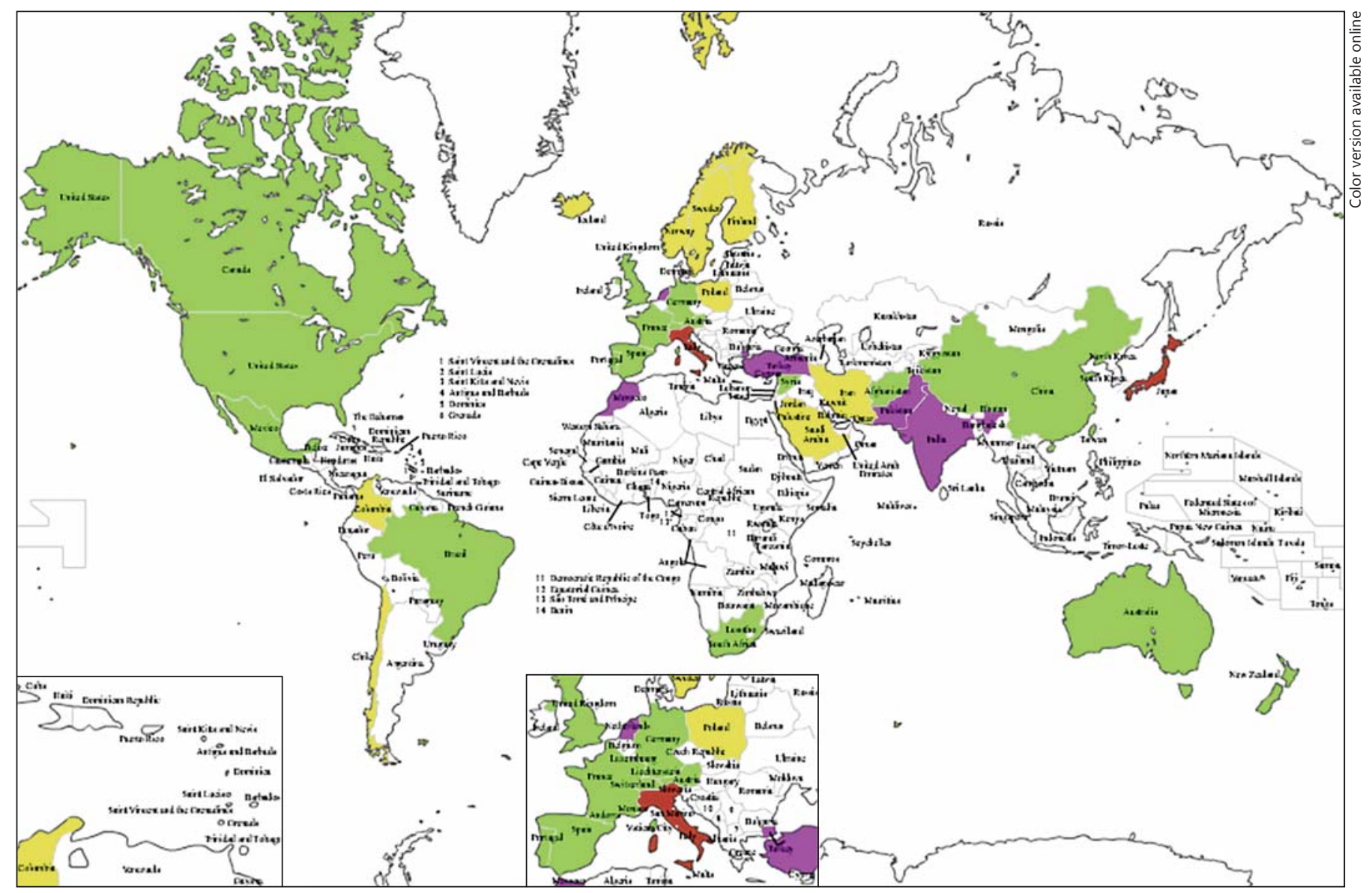

Fig. 1. Map of the counties with reported WS patients and AWS cases referred to our Registry. WS patients with demonstrated $W R N$ mutations have been identified in countries in green. Founder mutations have been are reported in Japan and Sardinia (red).

mutations, and 49 AWS cases that have neither WRN nor LMNA mutations. AWS subjects in our Registry range from age 10 to 66 years and are from all over the world. A progeroid appearance was the reason of referral in virtually all cases, but they have various additional features such as skeletal abnormalities or mild mental retardation, which are not commonly seen in classical WS. Of 49,7 cases meet criteria for 'definite' or 'probable' WS, 37 cases meet criteria for 'possible' WS, and 5 have exclusion criteria [2]. One of the major difficulties of further classifying AWS has been that the patients are of different ethnic backgrounds where normal age-related features vary from country to country.

Eleven years prior to the cloning of the WRN gene in 1996, Imura et al. [3] grouped atypical cases of WS into three clusters solely based on the clinical features: group 1 were of normal body height, group 2 had no sign of
Ethnic-specific mutations have been observed in Indian/Pakistani, Turk, Moroccan and Dutch WS patients (pink) [16]. AWS but not WS patients have been referred to the Registry from the countries in yellow.

cataract, and group 3 had normal or almost normal gonadal function. In group 1, onset tended to be late, bone changes and hypogonadism were infrequent, and the frequency of skin manifestations was high. Group 2 patients were usually of short stature, had skin or hair changes and bone abnormalities less frequently, and onset of the disease tended to be early. Group 3 patients had a history of onset after puberty and a less frequent association of short stature, skin ulcers, hair abnormalities, and osteoporosis. There were no differences in the incidence of consanguineous matings and familial occurrence among the three groups. Although WS is considered to be an abnormality of one major gene, $W R N$, the complex combination of clinical manifestations is not uniform, even in typical cases. In addition, there are likely to be a number of other disease entities whose presentations are similar to WS but are caused by mutations in other loci. 


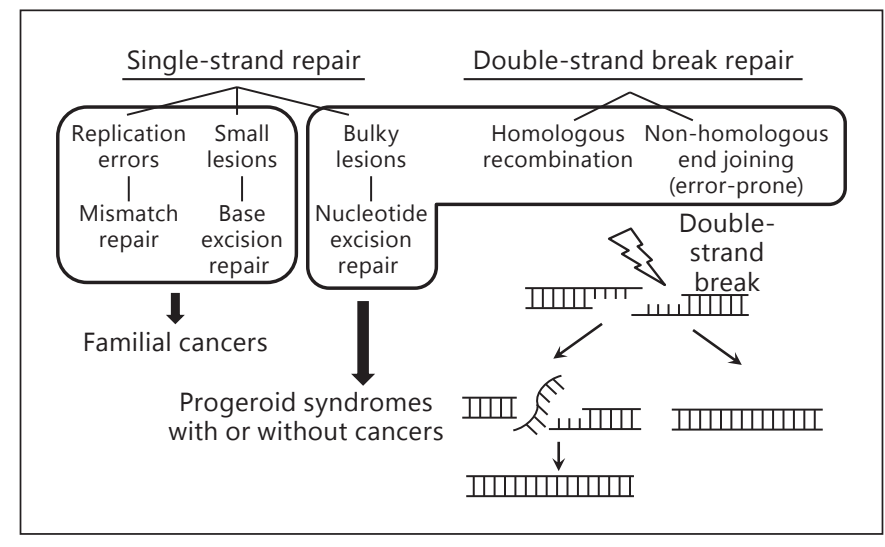

Fig. 2. Major DNA repair pathways in mammalian cells relevant to progeroid syndromes.

\section{Genetic Causes of Progeroid Syndromes}

Progeroid syndromes are groups of disorders that present features suggestive of accelerated aging. Segmental progeroid syndromes affect multiple organs and tissues, whereas unimodal syndromes predominantly impact a single organ (e.g. dementia of the Alzheimer type) [4]. The best known examples of segmental progeroid syndromes are WS caused by WRN gene mutations and Hutchinson-Gilford progeria syndrome (HGPS) caused by $L M N A$ mutations. The responsible mutations include those that impact genomic stability, nuclear structure, the number of triplet repeats and cause alterations in lipid and carbohydrate metabolism. Some chromosomal aneuploidies (e.g. trisomy 21) also exhibit segmental progeroid features [4].

Genomic instability syndromes are a major category of segmental progeroid syndromes [4]. They result from mutations in DNA repair genes, including those involved in single- and double-strand break (DSB) repair (fig. 2) [5]. Among the single-strand repair pathways, nucleotide excision repair removes damaged nucleotides. They can be further classified into those with impact upon global genome repair and transcription-coupled repair, which removes lesions in the transcribed strand of active genes [5]. Mutations in transcription-coupled repair have been identified in Weber-Cockayne syndrome, a genomic instability syndrome with progeroid features [6].

DSBs are potentially more detrimental to cells than single-strand breaks. The repair of DSBs in eukaryotic cells occurs through one of two different mechanisms, homologous recombination (HR) or non-homologous end joining (NHEJ). For HR and NHEJ, the optimum
DSB repair processes require RecQ-type DNA helicases. WS, the canonical adult-onset segmental progeroid syndrome, is caused by mutations in a locus that encodes a member of the RecQ family of helicases. Although nuclear intermediate filaments, lamin $\mathrm{A} / \mathrm{C}$, encoded by the LMNA gene, has not been directly linked to the DSB repair pathway, the accumulation of DSBs has been reported in HGPS and other LMNA mutant fibroblasts [7, 8].

A subset of HGPS and restrictive dermopathy (RD) are caused by mutations of ZMPSTE24, which encodes the endoprotease required for the maturation of prelamin $A$ to lamin A [9]. A related progeroid syndrome, NéstorGuillermo progeria syndrome (NGPS), is caused by mutations of BANF1 (barrier to autointegration factor 1) which encodes a nuclear lamina-associated gene [10]. Key features of NGPS include onset in early childhood, short stature, a characteristic facial appearance with proptosis, micrognathia with mandibular osteolysis, sparse eyebrows, eyelashes and scalp hair, lipodystrophy, severe osteolysis and osteoporosis, but without atherosclerosis or diabetes. NGPS is compatible with survival into adulthood. Because of the relatively young onset, classical HGPS, RD and NGPS are unlikely to be diagnosed clinically as WS. Nevertheless, the nuclear lamina-associated genes constitute another group of progeroid syndrome loci.

Genetic causes of segmental progeroid syndrome vary widely, despite overlapping clinical features. For example, in a subset of patients with clinical features of WS, only some cases have identifiable mutations in WRN. A comprehensive search is therefore warranted to identify other causative loci, followed by mechanistic studies on the nature of the various gene actions and how these may overlap with mechanisms of oncogenesis and normative aging.

\section{Classical Werner Syndrome}

The clinical phenotype of WS (WS; MIM\#277700) has been succinctly summarized as a 'caricature of aging' [2, 11-13] (fig. 3). WS patients are born normal, and have normal growth, development and cognitive function in childhood. The first clinical sign is a lack of the expected pubertal growth spurt during the teen years. WS affects multiple organ systems and results in the premature onset of age-related diseases such as cataracts, cancer and cardiovascular disease. Beginning in the teens or 20s, the typical features of WS begin to be evident. The face has an overall prematurely aged appear- 


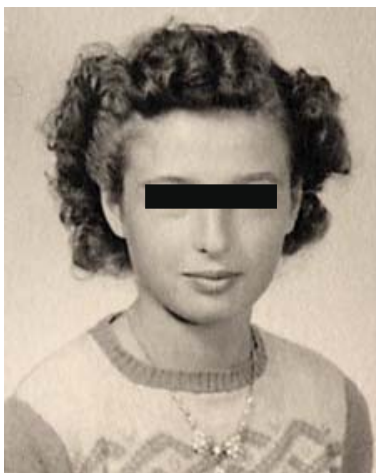

Age 8

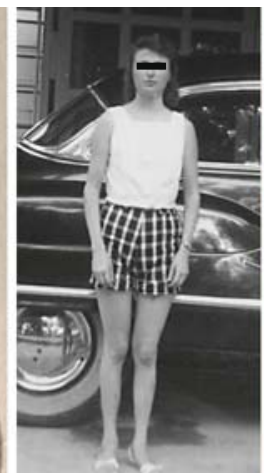

Age 21

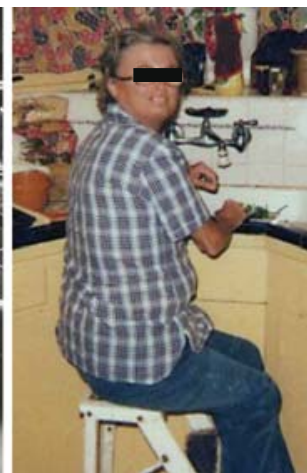

Age 36

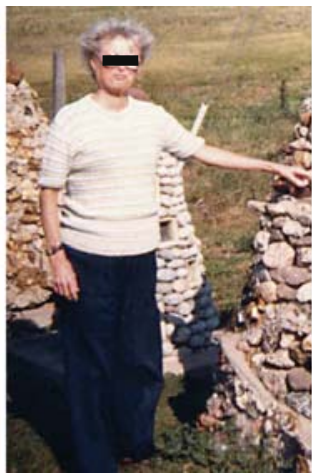

Age 48

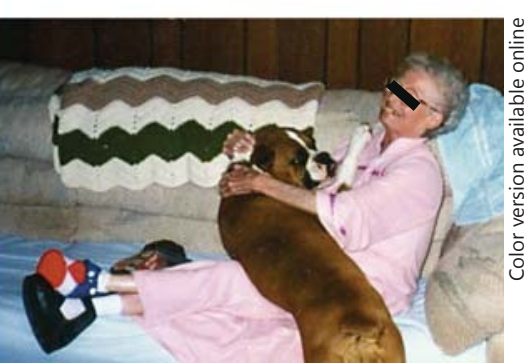

Age 56

Fig. 3. A WS patient with homozygous null $W R N$ mutations. Although apparently normal at ages 8 , cataracts were removed at age 36 and severe ankle ulcerations were recorded at age 56 [33].

ance, and may acquire a 'bird-like' appearance. The voice is high-pitched or hoarse. The skin is thin, taut, with loss of subcutaneous fat and areas of hypo- and hyperpigmentation. Fat loss is often associated with characteristic ulcerations around the ankles (and, occasionally, the elbows) which eventually may require lower limb amputation. The hair is prematurely gray and thin. The extremities become thin, from atrophy of muscle and subcutaneous tissue. X-rays may reveal osteosclerosis of the distal phalanges or soft tissue calcification. Both men and women have hypogonadism, with atrophic genitalia, and infertility, and women go through early menopause. Other complications typically beginning in the 30s include type 2 diabetes mellitus; osteoporosis (especially of the lower limbs, in contrast to the preferential involvement of vertebrae in usual aging); bilateral ocular cataracts (requiring surgery at a median age of 30); hypertension, premature and severe forms of arteriosclerosis (including atherosclerosis, arteriolosclerosis and medial calcinosis), calcification of the heart valves, and peripheral neuropathy. Multiple cancers have been observed by middle age. In contrast to the types of cancers associated with usual aging, these include a disproportionate number of sarcomas. Meningiomas and thyroid cancer have been reported in WS. There is not an increase in agerelated neurodegenerative diseases such as Alzheimer disease, Parkinson disease, or amyotrophic lateral sclerosis. The family history can be helpful to establish the diagnosis, if there is a history of parental consanguinity, or an affected sibling. WS is known to occur worldwide, but is more prevalent in Japan and Sardinia. Our survey of WS patients with a molecularly confirmed diagnosis revealed that the prevalence of cataracts was $100 \%$
(87/87) by age 30 [14]. The prevalence of osteoporosis was $91 \%$, hypogonadism $80 \%$, diabetes mellitus $71 \%$, and atherosclerosis $40 \%$ at the time of diagnosis. The median age of death in the most recent study was 54 years, a significant increase over what had been observed several decades ago [11], perhaps the result of improved medical management. These findings are remarkably similar to the survey of WS patients in Japan $[12,13]$. The most common cause of death was myocardial infarction in our study [14] and was malignancy is Japan [12].

\section{WRN Disease Mutations in WS Patients}

The gene $(W R N)$ responsible for WS encodes a 180$\mathrm{kDa}$ multifunctional nuclear protein that belongs to the family of RecQ-type helicase [1]. Sequence analysis and subsequent biochemical studies revealed that the human WRN protein possesses both exonuclease and helicase functions [15]. Figure 4 shows the locations and amino acid changes caused by such mutations, categorized by the types of mutation [16]. The majority of these mutations result in truncations of the nuclear localization signals at the C-termini of the proteins and/or nonsensemediated decay of the mutant mRNAs; these are therefore null mutations. There also are five reported missense mutations: K125N, K135E, G574R, R637W and M1350R. The K125N and K135 mutations were found to disrupt protein structure and cause protein instability, again resulting in a null mutation [14] while G574R mutation was shown to inhibit ATP binding, and thereby leads to a significant decrease in helicase activity [17]. 


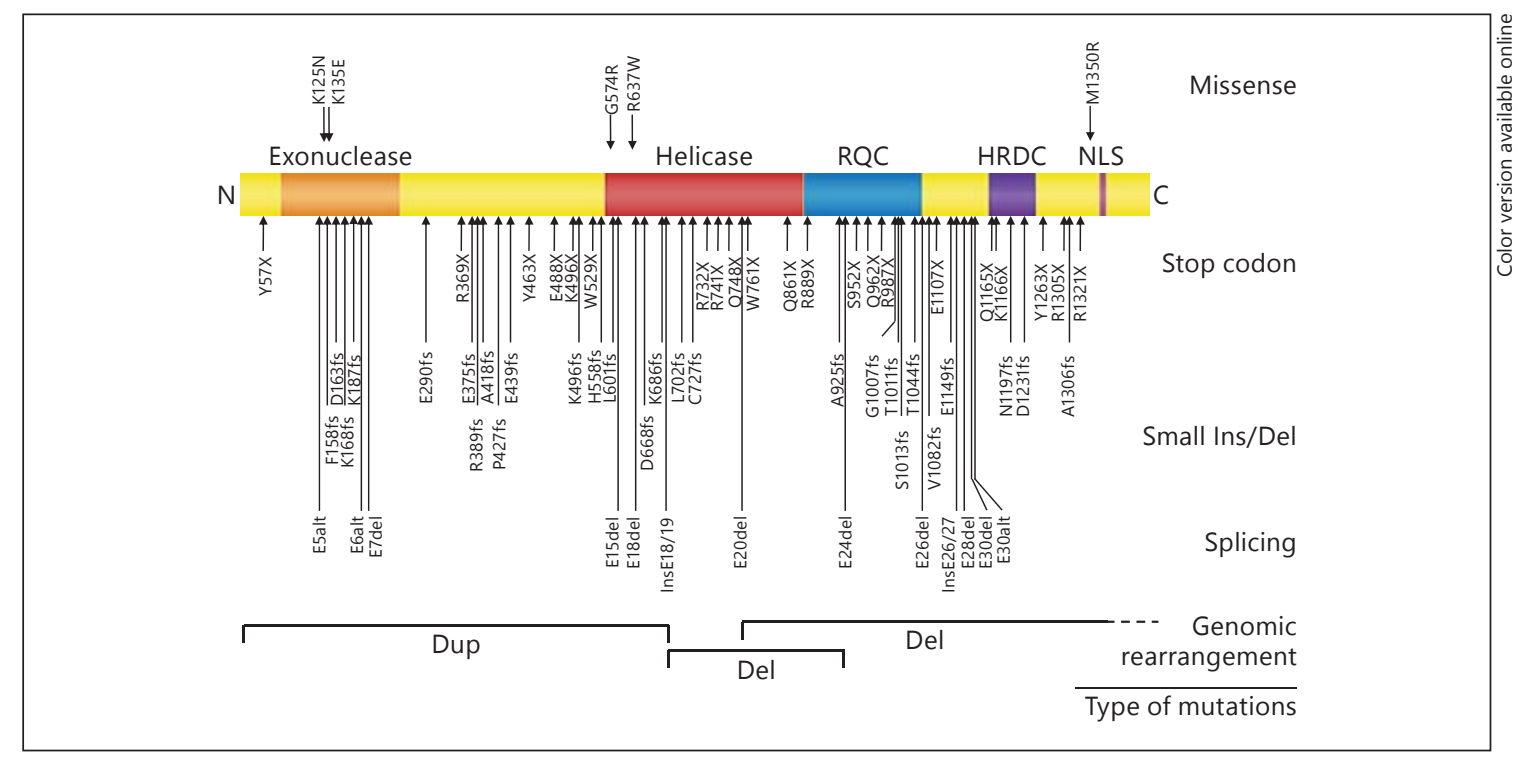

Fig. 4. $W R N$ disease mutations in classical WS patients. Rectangular box shows the WRN protein with $\mathrm{N}$-terminus on the left and $\mathrm{C}$-terminus on the right. Known functional domains include an exonuclease region (Exo), a helicase region, a RecQ C-terminus consensus region (RQC), a helicase domain, an RnaseD consensus region (HRDC), and a nuclear localization signal (NLS). Mutations are grouped based on the types of mutations: missense, stop codon, insertion/deletion or splicing mutation. Arrows indicate the location of the mutations and the amino acid changes caused by the mutations. Splicing mutations are indicated by the affected exons. Deep intron mutations that create new exons are indicated as 'Ins' along with the flanking exons. Splice mutations that result in the use of alternative splice sites ('alt') are indicated as such. Genomic rearrangements, either deletion (Del) or duplication (Dup) are shown at corresponding protein locations, with regions extending beyond this figure in dotted lines [16].
Fig. 5. LMNA mutations in AWS. The diagram shows the structure of lamin A. It consists of globular head domain, linker regions, $\alpha$-helical coiled coil domain and globular tail domain. Heterozygous amino acid changes seen in AWS are also shown. Left photo shows a 36-year-old AWS patient with L140R mutation who has cataracts, osteoporosis and an aged appearance. Right photo shows a 37-year-old man with an exon 11 splicing mutation who had multiple episodes of myocardial infarction and whose facial appearance suggests precocious aging [34].

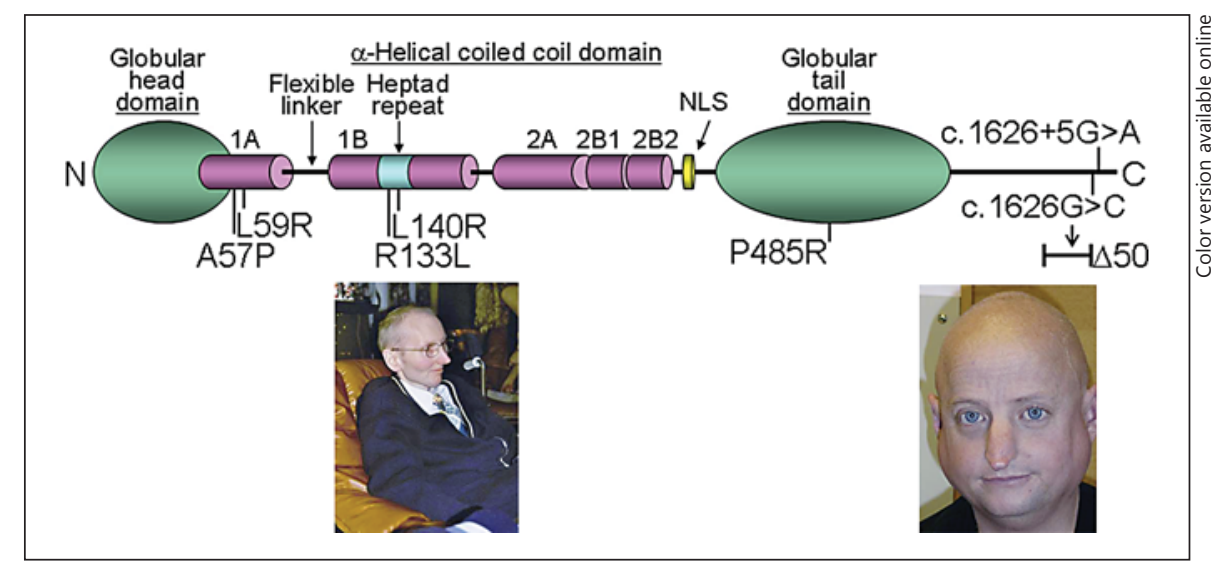

\section{LMNA Mutations in a Subset of AWS Patients}

A subset of AWS patients carry heterozygous LMNA mutations [18]. The LMNA gene encodes nuclear intermediate filaments, lamin A and lamin C [19]. The mature lamin A molecule consists of a globular head domain, a-helical coiled coil domain, and globular tail domain (fig. 5). Within the $\alpha$-helical coiled coil domain, there is a heptad repeat region that is thought to be involved in molecular interactions.

There are two groups of $L M N A$ mutation that give rise to AWS. One group consists of missense mutations: A57P, L59R, R133L, L140R and P485R [18] (fig. 5). These LMNA mutant AWS patients exhibited younger onset compared to patients with classical WS, resembling the group 2 subtype described in the above-mentioned paper by Imura et 
al. [3]. The locations of R133L and L140R at the surface of a heptad repeat suggested that the mutations might not affect the structure of the lamin A/C dimer itself, but might perturb intermolecular interactions [19] (fig. 5).

A second group consists of heterozygous substitutions at the junction of $L M N A$ exon 11 and intron 11, namely c. $1968 \mathrm{G}>\mathrm{A}$ and c. $1968+5 \mathrm{G}>\mathrm{A}$, as found in a 36-year-old man (fig. 5) and a 46-year-old woman with progeroid features and a history of myocardial infarction. These alterations lead to the weak activation of the same cryptic splicing site as in HGPS where virtually all the patients die of myocardial infarction at a median age of 13 [20]. A majority of HPGS is caused by a single point mutation within exon 11 of $L M N A$, which generates a cryptic splicing site and causes a 50-amino-acid in-frame deletion [21, 22]. The relatively low levels of progerin found in our patients are consistent with the clinical picture of late-onset symptoms.

\section{Chromosomal Abnormalities, Genomic Rearrangements and Progeroid Syndromes}

Recent technological advances in high-resolution chromosomal analyses have revealed that copy number variations represent a major source of diversity in human populations [23]. We conducted array CGH analysis in selected AWS patients and identified a case of possible mosaic trisomy 8. Further cytogenetic analysis of skin fibroblast cultures revealed a mosaic type of trisomy 8 $(47, \mathrm{XX},+8[4] / 46, \mathrm{XX}[1])$. There is evidence that trisomy- 8 cells exit the cell cycle prematurely [24]. This might contribute to cell loss and tissue atrophy, thus resulting in some clinical progeroid features, as was the case in this patient. As array CGH becomes a routine laboratory test, we expect to identify more cases with chromosomal abnormalities and genomic rearrangements that lead to progeroid features.

\section{Implications of Progeroid Syndromes for Normal Aging}

We now know that gene actions in progeroid syndrome, originally discovered in patients with rare disorders, play a much wider role in normal aging processes, the pathogenesis of common age-related disorders, including cancer, and the modulation of human longevity.

Our earlier studies demonstrated an association between common WRN polymorphisms, namely Leu-
1074Phe and Cys1367Arg, and the severity of coronary atherosclerosis as well as longevity [25]. The New England Centenarian Study further confirmed the association between Leu1074Phe and exceptional longevity as well as age of onset of cardiovascular disease [26]. Leu1074Phe is located between RQC and HRDC domains where WRN interacts with various nuclear proteins including TRF2 (fig. 3) [15]. Cys1367Arg is located 4 amino acids away from the nuclear localization signal. Such observations suggest a functional significance for these polymorphisms.

Several laboratories have demonstrated the accumulation of progerin in senescent cells in culture or in cells derived from normal, older individuals, suggesting a role for progerin in normal aging processes [27]. One study showed an increase of progerin by an average of 3\% per year in the coronary arteries of normal individuals [28]. Moreover, studies of four independent centenarian populations revealed an association between lifespan and LMNA haplotype $[26,29]$. Basic research on the underlying mechanisms of LMNA mutations therefore has the potential to lead to rational approaches to the prevention and treatment of coronary atherosclerosis, the most frequent cause of mortality in our society.

\section{Conclusion}

Genetic causes of segmental progeroid syndromes range from single nucleotide changes to trinucleotide expansions to chromosomal or structural abnormalities to the unknown. The protein functions encoded by the causative genes vary widely - from carbohydrate metabolism to DNA repair to structural proteins. Even cases characterized as clinically 'definite WS', although most commonly caused by WRN mutations, are likely to be genetically heterogeneous, given the experience of our International Registry. A systematic genome-wide search of the genetic causes is therefore warranted to identify the basis of a wider array of progeroid syndromes. Thanks to recent advances in next-generation sequencing, this has become feasible.

We have already noted the generalization of genomic instability as one fundamental process underlying progeroid syndromes. The importance of genomic instability in normative aging has major support from a variety of studies documenting increasing loads of somatic mutation with aging. We anticipate that other such overlapping phenomena will be revealed via the discovery of new loci associated with AWS. Interestingly, the accu- 
mulation of DNA damage seen in progeroid syndromes relates to a potentially unifying hypothesis across species, as originally proposed as a free radical theory of aging by Harman [30]. It has been proposed that agingassociated inflammation may lead to the production of excessive free radicals in older individuals as well as WS patients [31,32]. A fuller picture of the underlying pathogenetic mechanisms of progeroid patterns of aging should provide guidance for new avenues of research, especially regarding the molecular biology of cancer and aging.

\section{Acknowledgement}

This work was supported by grant AG04328 from the NIH.

\section{References}

1 Yu CE, Oshima J, Fu YH, Wijsman EM, Hisama F, Alisch R, Matthews S, Nakura J, Miki T, Ouais S, Martin GM, Mulligan J, Schellenberg GD: Positional cloning of the Werner's syndrome gene. Science 1996;272:258-262.

2 Oshima J, Martin GM, Hisama FM: Werner syndrome; in Pagon RA, Adam MP, Bird TD, Dolan CR, Fong CT, Stephens K (eds): GeneReviews ${ }^{\mathrm{TM}}$. Seattle, University of Washington, 2013.

-3 Imura H, Nakao Y, Kuzuya H, Okamoto M, Okamoto M, Yamada K: Clinical, endocrine and metabolic aspects of the Werner syndrome compared with those of normal aging. Adv Exp Med Biol 1985;190:171-185.

4 Martin GM, Oshima J: Lessons from human progeroid syndromes. Nature 2000;408:263266.

$\checkmark 5$ Gorbunova V, Seluanov A, Mao Z, Hine C: Changes in DNA repair during aging. Nucleic Acids Res 2007;35:7466-7474.

-6 Laugel V, Dalloz C, Durand M, Sauvanaud F, Kristensen U, Vincent MC, Pasquier L, Odent S, Cormier-Daire V, Gener B, Tobias ES, Tolmie JL, Martin-Coignard D, Drouin-Garraud V, Heron D, Journel H, Raffo E, Vigneron J, Lyonnet S, Murday V, Gubser-Mercati D, Funalot B, Brueton L, Sanchez Del Pozo J, Munoz E, Gennery AR, Salih M, Noruzinia M, Prescott K, Ramos L, Stark Z, Fieggen K, Chabrol B, Sarda P, Edery P, Bloch-Zupan A, Fawcett H, Pham D, Egly JM, Lehmann AR, Sarasin A, Dollfus $\mathrm{H}$ : Mutation update for the CSB/ERCC6 and CSA/ERCC8 genes involved in Cockayne syndrome. Hum Mutat 2010;31:113-126.

7 Gonzalez-Suarez I, Gonzalo S: Nurturing the genome: A-type lamins preserve genomic stability. Nucleus 2010;1:129-135.

8 Musich PR, Zou Y: Genomic instability and DNA damage responses in progeria arising from defective maturation of prelamin $\mathrm{A}$. Aging (Albany NY) 2009;1:28-37.

-9 Navarro CL, Cadinanos J, De Sandre-Giovannoli A, Bernard R, Courrier S, Boccaccio I, Boyer A, Kleijer WJ, Wagner A, Giuliano F, Beemer FA, Freije JM, Cau P, Hennekam RC, Lopez-Otin C, Badens C, Levy N: Loss of ZMPSTE24 (FACE-1) causes autosomal recessive restrictive dermopathy and accumulation of lamin A precursors. Hum Mol Genet 2005;14:1503-1513.
10 Cabanillas R, Cadinanos J, Villameytide JA, Perez M, Longo J, Richard JM, Alvarez R, Duran NS, Illan R, Gonzalez DJ, Lopez-Otin C: Néstor-Guillermo progeria syndrome: a novel premature aging condition with early onset and chronic development caused by BANF1 mutations. Am J Med Genet A 2011;155A: 2617-2625.

-11 Epstein CJ, Martin GM, Schultz AL, Motulsky AG: Werner's syndrome a review of its symptomatology, natural history, pathologic features, genetics and relationship to the natural aging process. Medicine (Baltimore) 1966;45: 177-221.

12 Goto M, Ishikawa Y, Sugimoto M, Furuichi Y: Werner syndrome: a changing pattern of clinical manifestations in Japan (1917-2008). Biosci Trends 2013;7:13-22.

13 Takemoto M, Mori S, Kuzuya M, Yoshimoto S, Shimamoto A, Igarashi M, Tanaka Y, Miki T, Yokote K: Diagnostic criteria for Werner syndrome based on Japanese nationwide epidemiological survey. Geriatr Gerontol Int 2013;13:475-481.

14 Huang S, Lee L, Hanson NB, Lenaerts C, Hoehn H, Poot M, Rubin CD, Chen DF, Yang CC, Juch H, Dorn T, Spiegel R, Oral EA, Abid M, Battisti C, Lucci-Cordisco E, Neri G, Steed EH, Kidd A, Isley W, Showalter D, Vittone JL, Konstantinow A, Ring J, Meyer P, Wenger SL, von Herbay A, Wollina U, Schuelke M, Huizenga CR, Leistritz DF, Martin GM, Mian IS, Oshima J: The spectrum of WRN mutations in Werner syndrome patients. Hum Mutat 2006;27:558-567.

15 Rossi ML, Ghosh AK, Bohr VA: Roles of Werner syndrome protein in protection of genome integrity. DNA Repair (Amst) 2010;9: 331-344.

16 Friedrich K, Lee L, Leistritz DF, Nurnberg G, Saha B, Hisama FM, Eyman DK, Lessel D, Nurnberg P, Li C, Garcia FVMJ, Kets CM, Schmidtke J, Cruz VT, Van den Akker PC, Boak J, Peter D, Compoginis G, Cefle K, Ozturk S, Lopez N, Wessel T, Poot M, Ippel PF, Groff-Kellermann B, Hoehn H, Martin GM, Kubisch C, Oshima J: WRN mutations in Werner syndrome patients: genomic rearrangements, unusual intronic mutations and ethnic-specific alterations. Hum Genet 2010; 128:103-111.
17 Tadokoro T, Rybanska-Spaeder I, Kulikowicz T, Dawut L, Oshima J, Croteau DL, Bohr VA: Functional deficit associated with a missense Werner syndrome mutation. DNA Repair (Amst) 2013;12:414-421.

18 Chen L, Lee L, Kudlow BA, Dos Santos HG Sletvold O, Shafeghati Y, Botha EG, Garg A, Hanson NB, Martin GM, Mian IS, Kennedy BK, Oshima J: LMNA mutations in atypical Werner's syndrome. Lancet 2003;362:440445 .

19 Worman HJ: Nuclear lamins and laminopathies. J Pathol 2012;226:316-325.

20 Merideth MA, Gordon LB, Clauss S, Sachdev V, Smith AC, Perry MB, Brewer CC, Zalewski C, Kim HJ, Solomon B, Brooks BP, Gerber LH, Turner ML, Domingo DL, Hart TC, Graf J, Reynolds JC, Gropman A, Yanovski JA, Gerhard-Herman M, Collins FS, Nabel EG, Cannon RO 3rd, Gahl WA, Introne WJ: Phenotype and course of Hutchinson-Gilford progeria syndrome. N Engl J Med 2008;358: 592-604.

21 De Sandre-Giovannoli A, Bernard R, Cau P, Navarro C, Amiel J, Boccaccio I, Lyonnet S, Stewart CL, Munnich A, Le Merrer M, Levy $\mathrm{N}$ : Lamin A truncation in Hutchinson-Gilford progeria. Science 2003;300:2055.

22 Eriksson M, Brown WT, Gordon LB, Glynn MW, Singer J, Scott L, Erdos MR, Robbins CM, Moses TY, Berglund P, Dutra A, Pak E, Durkin S, Csoka AB, Boehnke M, Glover TW, Collins FS: Recurrent de novo point mutations in lamin A cause Hutchinson-Gilford progeria syndrome. Nature 2003;423:293-

23 Gonzaga-Jauregui C, Lupski JR, Gibbs RA: Human genome sequencing in health and disease. Annu Rev Med 2012;63:35-61.

24 Hulley BJ, Hummel M, Cook LL, Boyd BK, Wenger SL: Trisomy-8 mosaicism: selective growth advantage of normal cells versus growth disadvantage of trisomy- 8 cells. Am J Med Genet A 2003;116A:144-146.

25 Castro E, Edland SD, Lee L, Ogburn CE, Deeb SS, Brown G, Panduro A, Riestra R, Tilvis R, Louhija J, Penttinen R, Erkkola R, Wang L, Martin GM, Oshima J: Polymorphisms at the Werner locus. II. 1074Leu/Phe, 1367Cys/Arg, longevity, and atherosclerosis. Am J Med Genet 2000;95:374-380. 
26 Sebastiani P, Solovieff N, Dewan AT, Walsh KM, Puca A, Hartley SW, Melista E, Andersen S, Dworkis DA, Wilk JB, Myers RH, Steinberg $\mathrm{MH}$, Montano M, Baldwin CT, Hoh J, Perls TT: Genetic signatures of exceptional longevity in humans. PLoS One 2012;7:e29848.

-27 Scaffidi P, Misteli T: Lamin A-dependent nuclear defects in human aging. Science 2006; 312:1059-1063.

28 Olive M, Harten I, Mitchell R, Beers JK, Djabali K, Cao K, Erdos MR, Blair C, Funke B, Smoot L, Gerhard-Herman M, Machan JT, Kutys R, Virmani R, Collins FS, Wight TN, Nabel EG, Gordon LB: Cardiovascular pathology in Hutchinson-Gilford progeria: correlation with the vascular pathology of aging. Arterioscler Thromb Vasc Biol 2010;30: 2301-2309.
29 Conneely KN, Capell BC, Erdos MR, Sebastiani P, Solovieff N, Swift AJ, Baldwin CT, Budagov T, Barzilai N, Atzmon G, Puca AA, Perls TT, Geesaman BJ, Boehnke M, Collins FS: Human longevity and common variations in the LMNA gene: a meta-analysis. Aging Cell 2012;11:475-481.

30 Harman D: Aging: a theory based on free radical and radiation chemistry. J Gerontol 1956; 11:298-300.

31 Goto M: Inflammaging (inflammation + aging): a driving force for human aging based on an evolutionarily antagonistic pleiotropy theory? Biosci Trends 2008;2:218-230.
32 Goto M, Sugimoto K, Hayashi S, Ogino T, Sugimoto M, Furuichi Y, Matsuura M, Ishikawa Y, Iwaki-Egawa S, Watanabe Y: Aging-associated inflammation in healthy Japanese individuals and patients with Werner syndrome. Exp Gerontol 2012;47:936-939.

- 33 Hisama FM, Bohr VA, Oshima J: WRN's tenth anniversary. Sci Aging Knowledge Environ 2006;2006:pe18.

34 Hisama FM, Lessel D, Leistritz D, Friedrich K, McBride KL, Pastore MT, Gottesman GS, Saha B, Martin GM, Kubisch C, Oshima J: Coronary artery disease in a Werner syndrome-like form of progeria characterized by low levels of progerin, a splice variant of lamin A. Am J Med Genet A 2011;155A:30023006. 